CLINICAL STUDY

\title{
Vitamin D absorption: consequences of gastric bypass surgery
}

\author{
Edo Aarts ${ }^{1}$, Lenneke van Groningen ${ }^{2}$, Ronald Horst ${ }^{3}$, Darryl Telting ${ }^{4}$, Adriaan van Sorge ${ }^{5}$, Ignace Janssen ${ }^{1}$ \\ and Hans de Boer ${ }^{2}$ \\ Departments of ${ }^{1}$ Surgery and ${ }^{2}$ Internal Medicine, Rijnstate Hospital, Wagnerlaan 55, 6800 TA Arnhem, The Netherlands, ${ }^{3}$ Heartland Assays, Inc., 2325 \\ North Loop Drive, Suite 6300, Ames, Iowa 50010, USA, Departments of ${ }^{4}$ Clinical Chemistry and ${ }^{5}$ Clinical Pharmacology, Rijnstate Hospital, \\ Wagnerlaan 55, 6800 TA Arnhem, The Netherlands \\ (Correspondence should be addressed to H de Boer; Email: hdeboer@alysis.nl)
}

\begin{abstract}
Background: Severe vitamin D deficiency is a common finding in morbid obesity, and the incidence increases markedly after RYGB. Normalization of vitamin D levels after RYGB is difficult to achieve because the degree of surgery-induced malabsorption is not known.

Objective: To develop a test that quantifies the changes in intestinal cholecalciferol absorption induced by Roux-en-Y gastric bypass (RYGB) surgery.

Methods: Absorption characteristics of cholecalciferol were studied in 14 morbidly obese, premenopausal women before and 4 weeks after laparoscopic RYGB. Serum cholecalciferol levels were measured at baseline and 1, 2, 3, and 14 days after a single oral dose of 50000 IU solubilized cholecalciferol.

Results: Peak serum cholecalciferol levels were observed on day 1 in all patients. They were $26.6 \pm 3.7 \%$ lower after RYGB $(P=0.02)$. Inter-individual variability was high.

Conclusion: Peak cholecalciferol levels are reduced by about $25 \%$ after RYGB. Further analysis suggested that the timing of sampling in the current study was not optimal. This might have caused an underestimation of the true decrease in cholecalciferol absorption induced by RYGB.
\end{abstract}

European Journal of Endocrinology $164827-832$

\section{Introduction}

The Roux-en-Y gastric bypass (RYGB) is very effective in inducing weight loss in morbid obesity (1). However, it is also associated with several undesirable side effects such as the loss of bone mass. A 10\% reduction in bone mineral density in the first 2 years after RYGB is not uncommon (2).

The aetiology of post-RYGB bone loss is multi-factorial (3). Some loss may occur as a result of reduced mechanical loading of the skeleton because of massive weight loss (4). This is probably unavoidable, but other risk factors are preventable and should be addressed appropriately. Vitamin D deficiency, defined as a serum level $<50 \mathrm{nmol} / \mathrm{l}$, is very common in morbidly obese patients, even in those awaiting bariatric surgery (5). The reported prevalence of vitamin $\mathrm{D}$ deficiency prior to surgery ranges between 54 and $80 \%(6-8)$. These low vitamin D levels before surgery have been attributed to inadequate intake, a lifestyle of limited sun exposure, and decreased bioavailability of vitamin $\mathrm{D}$ due to sequestration of the fat-soluble vitamin in excess adipose tissue (9). As RYGB will impair intestinal vitamin D absorption, it will further increase the risk of developing vitamin D deficiency. The degree of RYGB-induced vitamin D malabsorption is presently not known. However, it appears that the length of the limb bypass is one of the determinants of postoperative vitamin D deficiency, i.e. vitamin D levels are lower after long-limb than after short-limb RYGB (10).

Preoperative normalization of calcium and vitamin D metabolism, individualized postoperative supplementation regimens, and rapid treatment of calcium and vitamin D deficits detected after surgery should become the corner stones for the prevention of bone loss after RYGB. To date, however, rational guidelines for preoperative correction of vitamin $\mathrm{D}$ deficits in morbid obese patients are not available $(11,12)$. Correction of postoperative vitamin $\mathrm{D}$ deficits is even more difficult to achieve because the dose adjustments that are needed to overcome malabsorption are presently not known. This lack of knowledge hampers the development of rational guidelines to correct postoperative calcium and vitamin $\mathrm{D}$ deficits. This study is focused on intestinal cholecalciferol absorption and attempts to quantify the changes induced by RYGB. There are two non-invasive approaches available to quantify intestinal cholecalciferol absorption: by measuring fractional faecal excretion of an oral dose of radiolabeled cholecalciferol or by measuring serum cholecalciferol levels after a single oral dose of unlabeled cholecalciferol (13). The former method is cumbersome, time consuming, not readily available in most institutions, and not suitable for outpatient use. As we wished to develop a diagnostic 
tool that would be applicable on an individual basis in a large number of patients, we chose to quantify cholecalciferol bioavailability based on measuring postabsorptive plasma levels.

\section{Patients and methods}

\section{Patients}

The study included 14 obese premenopausal women 20-50 years of age, with a body mass index (BMI) of $35-50 \mathrm{~kg} / \mathrm{m}^{2}$, and scheduled for laparoscopic RYGB (LRYGB) in the winter period of 2008-2009. Of the 14 patients, two had undergone a cholecystectomy previously. The time schedule was chosen to prevent any bias caused by the seasonal variation of cutaneous cholecalciferol production. The use of a solarium was not allowed. Exclusion criteria for participation were liver disease (liver enzymes $>2$ times the upper normal limit), kidney disease (glomerular filtration rate $(\mathrm{GFR})<60 \mathrm{ml} / \mathrm{min}$ ), gastrointestinal disorders suggestive of malabsorption, granulomatous disorders, diabetes mellitus $>10$ years, or clinical suspicion of diabetic gastroenteropathy, and medication known to affect vitamin D and bone metabolism (e.g. corticosteroids and anti-convulsive medication).

LRYGB was performed in a single centre by two dedicated bariatric surgeons who used the same techniques. All subjects received a $100 \mathrm{~cm}$ alimentary limb and a $40 \mathrm{~cm}$ biliopancreatic limb. Postoperatively, each patient was recommended to take multivitamins daily equivalent to $150 \%$ of the recommended daily allowance, omeprazole $40 \mathrm{mg}$ once a day, and a combination of calcium carbonate $500 \mathrm{mg}$ and vitamin $\mathrm{D}_{3}$ $400 \mathrm{IU}$ three times a day (Calcichew 500/400 tid). Low-molecular weight heparin was given s.c. once daily, for 6 weeks postoperatively. The study was approved by the Regional Institutional Review Board. Written informed consent was obtained from all patients.

\section{Methods}

Vitamin D status was checked at baseline. When the serum 25-hydroxyvitamin D (25-OHD) level was $<75 \mathrm{nmol} / \mathrm{l}$, the deficit was corrected with oral, solubilized cholecalciferol ${ }^{\mathrm{FNA}} 50000 \mathrm{IU} / \mathrm{ml}$, as described previously (14). Calculation of the loading dose needed to raise serum $25-\mathrm{OHD}$ to the target level of $75 \mathrm{nmol} / \mathrm{l}$ was based on the equation:

Loading Dose (IU)

$$
\begin{aligned}
= & 40 \times\left(75-\text { actual serum } 25-\mathrm{OHD}_{3} \text { level }\right) \\
& \times \text { body weight }
\end{aligned}
$$

The prescribed loading dose was equal to the calculated dose rounded off upward to a multiple of 25000 IU. The calculated dose was administered in divided portions of $50000 \mathrm{IU} / \mathrm{ml}$ and, if necessary, a final portion of 25000 IU. The gifts were administered on Monday, Wednesday, and Friday, until the total loading dose was reached. To check the results of vitamin D supplementation, serum 25-OHD levels were measured 14 days after the final dose.

The cholecalciferol absorption test was performed 4 weeks before and after LRYGB. The protocol required that a cholecalciferol absorption test should be scheduled at least 2 weeks after the completion of treatment for pre-existent vitamin $\mathrm{D}$ deficiency. After an overnight fast, a test dose of 50000 IU was administered orally at $0900 \mathrm{~h}$, in combination with $100 \mathrm{ml}$ vanilla flavoured custard. Serum cholecalciferol levels were measured over a period of 15 days, starting 1 day before the ingestion of the test dose $(T=-1)$, just before the ingestion of cholecalciferol $(T=0)$, and 1,2 , 3 , and 14 days after $(T=1,2,3$, and 14). In each subject, the timing $\left(T_{\max }\right)$ and the serum level of the peak cholecalciferol concentration $\left(C_{\text {max }}\right)$ was assessed, and the cholecalciferol area under the curve over days 0-3 (AUC) was calculated, before and after surgery.

\section{Measurements}

All blood samples were taken in the fasting state, between 0800 and $0900 \mathrm{~h}$. Serum cholecalciferol was measured by HPLC/u.v. light absorption analysis as described previously (15). This technique has a detection limit of $1.25 \mathrm{nmol} / \mathrm{l}$ and an intra- and interassay coefficient of variation of 8.3 and $11.4 \%$ respectively. Serum 25-OHD levels were measured by RIA (DiaSorin, Stillwater, MN, USA), with a total imprecision of $11 \%$. Serum 1,25-OHD levels were measured by RIA (Immunodiagnostic Systems GmbH, Frankfurt am Main, Germany), with an intra- and inter-assay precision of $<12$ and $<14 \%$ respectively. The analytical detection limits of the 25-OHD and 1,25-OHD assay (defined as the concentration corresponding to the mean -2 s.D.s of ten replicates of the zero calibrator) were $3.75 \mathrm{nmol} / \mathrm{l}$ and $8 \mathrm{pmol} / \mathrm{l}$ respectively. Serum intact parathyroid hormone (PTH) was measured by a solid-phase, two-site chemoluminiscent enzyme-labeled immunometric assay (Immulite 2500, Siemens, Los Angeles, CA, USA), with an intra- and inter-assay precision of $<6$ and $<9 \%$ respectively. The analytical sensitivity of this PTH assay was $0.3 \mathrm{pmol} / \mathrm{l}$.

\section{Statistical analysis}

Results are shown as mean values \pm s.e.m. Power analysis was based on the study of Armas et al. (16). This study showed that a single dose of $50000 \mathrm{IU}$ cholecalciferol briefly raised serum cholecalciferol by $30 \mathrm{nmol} / \mathrm{l}$ in ten healthy volunteers with a s.D. of $12 \mathrm{nmol} / \mathrm{l}$. A postoperative decline in $C_{\max }>25 \%$ was defined as clinically relevant, because a change of this magnitude was likely to require a dose adjustment. 
To be able to detect a $25 \%$ difference between preand post-operative $C_{\max }$ with $\alpha=0.05$ (one-sided) and $\beta=0.10$, and assuming a correlation coefficient of 0.70 between pre- and post-operative measurements, 14 patients needed to be tested. Pre- and post-operative results were compared by paired $t$-test. A $P$ value $<0.05$ was considered to be statistically significant.

\section{Results}

A total of 14 premenopausal women participated in the study. Their mean age was $37.0 \pm 2.1$ years, and they had a BMI of $44.9 \pm 1.7 \mathrm{~kg} / \mathrm{m}^{2}$ (range $\left.36.7-61.2 \mathrm{~kg} / \mathrm{m}^{2}\right)$. Mean serum 25-OHD at screening was $38.0 \pm 4.0 \mathrm{nmol} / \mathrm{l}$. Serum total calcium, phosphate albumin and PTH levels were within the normal range. Mean urinary calcium excretion was $3.4 \pm 0.5 \mathrm{mmol} / 24 \mathrm{~h}$. Of the 14 patients, nine patients had reduced urinary calcium excretion rates, i.e. a calcium excretion of $<4 \mathrm{mmol} / 24 \mathrm{~h}$. As shown in Fig. 1, 12 patients had a 25-OHD level $<50 \mathrm{nmol} / \mathrm{l}$ and two had a level between 50 and $75 \mathrm{nmol} / \mathrm{l}$. The calculated vitamin $\mathrm{D}$ deficit ranged from 16000 to $305000 \mathrm{IU}$, with a mean of 188366 \pm 22022 IU. All patients received oral cholecalciferol supplementation as described, the doses ranged from 25000 to 300000 IU. This regimen increased the mean 25-OHD level from $38.0 \pm 4.0$ to $76.5 \pm 3.1 \mathrm{nmol} / \mathrm{l}$ $(P<0.001)$. The post-supplementation level was $>50 \mathrm{nmol} / \mathrm{l}$ in all patients, five patients had a level between 50 and $75 \mathrm{nmol} / \mathrm{l}$ and nine had a level between 75 and $100 \mathrm{nmol} / \mathrm{l}$.

The main parameters of interest for this study, assessed on $T=0$ of the pre- and post-operative absorption tests, are summarized in Table 1. Mean weight decreased from $127.2 \pm 6.5$ to $115.0 \pm 6.2 \mathrm{~kg}(P<0.001)$. Baseline serum cholecalciferol was significantly higher preoperatively than postoperatively $(18.8 \pm 3.0$ vs

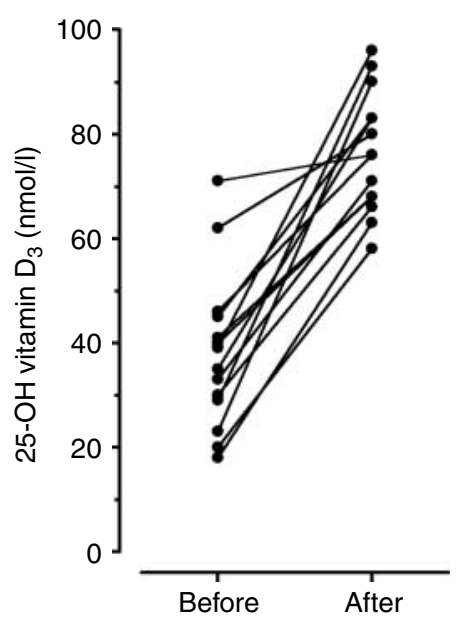

Figure 1 Preoperative serum 25-OH vitamin $\mathrm{D}_{3}$ levels before and after correction of the calculated vitamin D deficit by means of oral, solubilized cholecalciferol.
Table 1 Comparison of baseline characteristics at $T=0$ of the pre- and post-operative cholecalciferol absorption tests, shown as mean values \pm S.E.M.

\begin{tabular}{|c|c|c|c|}
\hline & Preoperative & Postoperative & $P$ value \\
\hline Weight (kg) & $127.2 \pm 6.5$ & $115.0 \pm 6.2$ & $<0.001$ \\
\hline Creatinine $(\mu \mathrm{mol} / \mathrm{l})$ & $64.8 \pm 1.8$ & $68.1 \pm 2.4$ & NS \\
\hline Albumin $(g / l)$ & $39.2 \pm 0.6$ & $40.4 \pm 0.6$ & NS \\
\hline $\begin{array}{l}\text { Total calcium } \\
(\mathrm{mmol} / \mathrm{l})\end{array}$ & $2.29 \pm 0.03$ & $2.33 \pm 0.02$ & NS \\
\hline Phosphate $(\mathrm{mmol} / \mathrm{l})$ & $1.02 \pm 0.04$ & $0.99 \pm 0.05$ & NS \\
\hline $\begin{array}{l}\text { Cholecalciferol } \\
\text { (nmol/l) }\end{array}$ & $18.8 \pm 3.0$ & $5.8 \pm 1.3$ & $<0.001$ \\
\hline $25-\mathrm{OHD}_{3}(\mathrm{nmol} / \mathrm{l})$ & $77.3 \pm 3.4$ & $74.4 \pm 4.2$ & NS \\
\hline $1,25-\mathrm{OHD}_{3}(\mathrm{pmol} / \mathrm{l})$ & $136 \pm 13$ & $138 \pm 10$ & NS \\
\hline PTH (pmol/l) & $3.5 \pm 0.5$ & $4.1 \pm 0.6$ & NS \\
\hline
\end{tabular}

$5.8 \pm 1.3 \mathrm{nmol} / \mathrm{l}, P<0.001)$, whereas all other parameters were not different on the two occasions. All patients had received cholecalciferol treatment preoperatively to correct the pre-existent vitamin D deficit. The interval between the final dose of cholecalciferol supplementation and the preoperative baseline measurement of serum cholecalciferol varied from 11 to 16 days and it was $<14$ days in two subjects. All patients received the standardized postoperative supplementation regimen as described earlier, until $T=-1$ of the postoperative cholecalciferol absorption test.

The mean changes in serum cholecalciferol levels in response to a single dose of $50000 \mathrm{IU}$ are shown in Fig. 2A on the left. In all patients, peak levels were observed on the first day after the oral dose, before as well as after surgery. The maximal change in serum cholecalciferol $\left(\Delta C_{\max }\right)$, defined as the difference between baseline and the highest post-absorptive level, varied markedly between patients. $\Delta C_{\max }$ ranged preoperatively from 43.3 to $118.5 \mathrm{nmol} / \mathrm{l}$, and postoperatively from 10.0 to $142.3 \mathrm{nmol} / \mathrm{l}$, i.e. the range widened after surgery (from $75.2 \mathrm{nmol} / \mathrm{l}$ preoperatively to $132 \mathrm{nmol} / \mathrm{l}$ postoperatively). The mean $\Delta C_{\max }$ decreased from 92 \pm 6.5 to $63.5 \pm 10.3 \mathrm{nmol} / \mathrm{l}$ after surgery, i.e. a decrease of $26.6 \pm 3.7 \%(P=0.02)$. As shown in Fig. $2 \mathrm{~B}, \Delta C_{\max }$ did not decrease in all subjects. Of the 14 patients, three patients demonstrated a post-surgery increase in $\Delta C_{\max }>10 \%$. The AUC-cholecalciferol measured over 3 days, and corrected for the difference in baseline $(\triangle \mathrm{AUC})$, did not change significantly $(59.0 \pm 4.4$ to $45.3 \pm 6.7 \mathrm{nmol} / \mathrm{l}$ per day, $P=0.09$ ).

\section{Discussion}

The aim of this study was to quantify the changes in intestinal cholecalciferol absorption induced by RYGB to serve as a starting point for the development of rational and individualized guidelines for dose adjustments to correct postoperative vitamin $\mathrm{D}$ deficits.

Preoperatively, all patients received solubilized cholecalciferol orally according to a recently published guideline to achieve a target level of $75 \mathrm{nmol} / \mathrm{l}(14)$. 

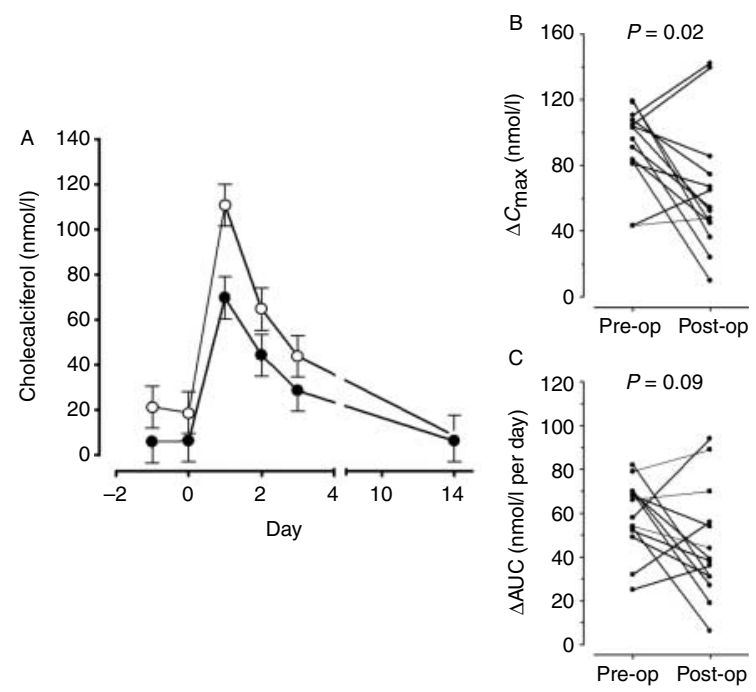

Figure 2 Changes in serum cholecalciferol level in response to a single dose of $50000 \mathrm{IU}$, before (open circles) and after gastric bypass (black dots). On the left: mean response, top right $\Delta C_{\max }$ cholecalciferol, and bottom right $\triangle \mathrm{AUC}$ cholecalciferol.

According to this guideline, the required loading dose can be calculated based on the basal serum 25-OHD level and body weight. The latter is important to adjust the vitamin $\mathrm{D}$ requirements for differences in distribution volume. Differences in distribution volume and sequestration of vitamin D in adipose tissue explain why peak serum levels after an oral dose of vitamin D are lower in obese than in non-obese subjects (9). Although the guideline referred to the above was developed for subjects weighing $<125 \mathrm{~kg}$, it performed very well in the obese women with body weights ranging from 98 to $177 \mathrm{~kg}$ (Fig. 1). The result of the treatment was very close to the target level of $75 \mathrm{nmol} / \mathrm{l}$. Although very promising, a further validation in a larger number of obese subjects will be necessary before this loading dose equation can be safely recommended for the rapid correction of vitamin D deficiency in morbid obesity. It may be of interest to examine whether correction for fat mass, as assessed by dual-energy X-ray absorptiometry or bio-impedance analysis, may serve to improve the accuracy of the loading dose equation in morbidly obese subjects.

Cholecalciferol absorption was studied by means of AUC cholecalciferol $(\triangle \mathrm{AUC})$ and by assessing the peak change in serum cholecalciferol $\left(\Delta C_{\max }\right)$. In this particular study design, $\Delta$ AUC was less sensitive to detect changes in cholecalciferol absorption than $\Delta C_{\max }$. The mean $\Delta C_{\max }$ decreased by about $25 \%$ after surgery. This was less than that expected. Clinical practice has taught us that the individual needs of post-RYGB patients vary greatly and that they may require a weekly dose between 25000 and $50000 \mathrm{IU}$ cholecalciferol to maintain their 25-OHD levels between 50 and $100 \mathrm{nmol} / \mathrm{l}$ (unpublished observations). In our experience, this is about four to eight times the amount required to maintain 25-OHD levels in normalweight subjects. Based on these findings, we expected to find a decrease in cholecalciferol absorption of at least $50-75 \%$.

In theory, there are several explanations for the relatively small decrease in peak absorption.

First, although we planned to do the postoperative absorption test as early as 4 weeks after surgery, the patients had already lost a mean of $12 \mathrm{~kg}$ in weight at that time. This reduces the distribution volume, which will cause a rise in $C_{\max }$ and the AUC, and thus masks the postoperative decrease in cholecalciferol absorption. Secondly, the timing of the sampling schedule may not be optimal and thus leads to an underestimation of the decrease in cholecalciferol bioavailability. As all subjects had their $T_{\max }$ (the point of time that $C_{\max }$ occurs) after $24 \mathrm{~h}$ and all serum cholecalciferol levels were lower at $48 \mathrm{~h}$, it is most likely that the true $T_{\max }$ must be somewhere in the first $24 \mathrm{~h}$. If that is the case, the $C_{\max }$ will be higher than the level measured after $24 \mathrm{~h}$. In addition, the individual's $T_{\max }$ may change after surgery. These issues will affect the estimated cholecalciferol bioavailability. We, therefore, conclude that more frequent sampling will be required during the first $48 \mathrm{~h}$ to determine the optimal sampling times, preoperatively as well as postoperatively.

Information regarding the cholecalciferol transport time from intestinal lumen to the blood compartment is essential to optimize the sampling times. Unfortunately, the literature is very scarce on this subject. Lymphatic transport is a major contributor of oral cholecalciferol bioavailability (17). After uptake into the enterocyte, cholecalciferol associates with intracellular lipoproteins that are subsequently exocytosed and taken up into the intestinal lymphatic system. Further transport occurs as chylomicrons through the intestinal lymphatic system to the systemic circulation. In rats, the appearance of orally administered $\mathrm{C}^{14}$-labelled cholecalciferol in the intestinal lymph starts after about $4 \mathrm{~h}$ with a rapid increase in recovery during the next $16 \mathrm{~h}$ and then a subsequent decline (18). These observations support the expectation that the preoperative $T_{\max }$ in humans will occur somewhere within the first $24 \mathrm{~h}$. Only two studies have described the first 24-h response to a single oral dose of 50000 IU vitamin D in healthy humans $(9,19)$. Both studies used ergocalciferol (vitamin $\mathrm{D}_{2}$ ) instead of cholecalciferol (vitamin $\mathrm{D}_{3}$ ), which we used. In the first study, the $50000 \mathrm{IU}$ oral dose was given to seven healthy volunteers, with samples taken at baseline and $4,8,12,24,48$, and $72 \mathrm{~h}$ afterward. Peak ergocalciferol levels were observed at $12 \mathrm{~h}$, with lower values at $24 \mathrm{~h}$ (19). In the second study, a single oral dose of $50000 \mathrm{IU}$ was given to 11 healthy subjects, and blood was sampled at baseline and 5, 10, and $25 \mathrm{~h}$. Maximal serum ergocalciferol levels were found at $10 \mathrm{~h} \mathrm{(9).} \mathrm{In} \mathrm{both} \mathrm{studies,} \mathrm{the}$ time interval between the sample with the peak concentration and the next sample was rather large, 
i.e. $12-14 \mathrm{~h}$, and it is conceivable that the true $T_{\max }$ is somewhere between 12 and $24 \mathrm{~h}$ after a single oral dose. The $T_{\text {max }}$ after gastric bypass is not known.

Initially, we assumed that the increased postoperative dose requirements to normalize serum 25-OHD levels were exclusively due to a decrease in cholecalciferol absorption. This might have been an oversimplification. Loss of cholecalciferol or 25-OHD as a result of an interrupted entero-hepatic cycle could also have been a factor. The hypothesis on entero-hepatic circulation of vitamin D was generated in the seventies based on observations in humans showing that considerable amounts of i.v. administered $\mathrm{H}^{3}$-labelled cholecalciferol or 25-OHD derivates appeared in the bile (20). Subsequent studies, however, revealed that vitamin D was mainly excreted as biologically inactive polar degradation products and that the amount of intact cholecalciferol or $25-\mathrm{OHD}$ was negligible $(21,22)$. It is now commonly concluded that the entero-hepatic circulation of vitamin $\mathrm{D}$ is nil.

In theory, the postoperative increase in cholecalciferol requirements could also be due to changes in vitamin D metabolism. Poorer hydroxylation of cholecalciferol, lowering of vitamin D binding protein, or increased breakdown of hydroxylated vitamin D would increase the required amount of cholecalciferol to maintain normal 25-OHD levels. So far, these issues have not been studied.

In this study, two unexpected observations deserve comments. First, the preoperative basal serum cholecalciferol levels were found to be significantly higher than the postoperative levels $(18.8 \pm 3.0$ vs 5.8 $\pm 1.3 \mathrm{nmol} / \mathrm{l}, \quad P<0.001)$. The interval of 2 weeks between the loading dose of cholecalciferol and the basal serum sample of the test might have been too short. Estimations are that about 14 days are required to convert the administered cholecalciferol into 25-OHD; however, in severely obese subjects this interval may be longer (23). Postoperatively, the time span between the latest cholecalciferol loading dose and the basal measurements was about 80 days, which is more than long enough to achieve steady state.

In contrast to our expectations, and despite the carefully controlled cholecalciferol ingestion procedure during the absorption test, three subjects demonstrated a postoperative peak $\Delta$-cholecalciferol that was more than $10 \%$ higher than the preoperative peak (Fig. 2). Apart from a measurement error, this unexpected observation may be related to changes in $T_{\max }$ after surgery. This is another argument to repeat the study with more frequent sampling during the first $48 \mathrm{~h}$ after the ingestion of the oral dose.

In conclusion, this study has shown that RYGB reduces the peak cholecalciferol levels by about $25 \%$. Substantial inter-individual variability was observed, and a methodical underestimation of the true decrease in cholecalciferol absorption is suspected. A repeat study with an optimized sampling time schedule is considered necessary to obtain a more reliable estimate of the change in cholecalciferol availability after RYGB. If that can be achieved, the cholecalciferol absorption test may become a useful instrument to predict the patient's cholecalciferol requirements early after bypass surgery. It is conceivable that in the long term, intestinal adaptation may change fractional cholecalciferol absorption and that it could be useful to repeat the test when weight loss is completed and body weight has stabilized.

\section{Declaration of interest}

The authors declare that there is no conflict of interest that could be perceived as prejudicing the impartiality of the research reported.

\section{Funding}

This research did not receive any specific grant from any funding agency in the public, commercial, or not-for-profit sector.

\section{References}

1 Buchwald H, Estok R, Fahrbach K, Banel D, Jenssen MD, Pories WJ, Bantle JP \& Sledge I. Weight and type 2 diabetes after bariatric surgery: systematic review and meta-analysis. American Journal of Medicine 2009122 248-256. (doi:10.1016/j.amjmed.2008.09. 041)

2 Coates PS, Fernstrom JD, Fernstrom MH, Schauer PR \& Greenspan SL. Gastric bypass surgery for morbid obesity leads to an increase in bone turnover and a decrease in bone mass. Journal of Clinical Endocrinology and Metabolism 200489 1061-1065. (doi:10.1210/jc.2003-031756)

3 De Prisco C \& Levine SN. Metabolic bone disease after gastric bypass surgery for obesity. American Journal of the Medical Sciences 2005329 57-61. (doi:10.1097/00000441-200502000-00001)

4 Leblanc A, Schneider V, Shackelford L, West S, Oganov V, Bakulin A \& Voronin L. Bone mineral and lean tissue loss after long duration space flight. Journal of Musculoskeletal and Neuronal Interactions 20001 157-160.

5 Malinowski SS. Nutritional and metabolic complications of bariatric surgery. American Journal of the Medical Sciences 2006 331 219-225. (doi:10.1097/00000441-200604000-00009)

6 Carlin AM, Rao DS, Meslemani AM, Genaw JA, Parikh NJ, Levy S, Bhan A \& Talpos GB. Prevalence of vitamin D depletion among obese patients seeking gastric bypass surgery. Surgery for Obesity and Related Diseases 20062 98-103. (doi:10.1016/j.soard.2005. 12.001)

7 Nelson ML, Bolduc LM, Toder ME, Clough DM \& Sullivan SS. Correction of preoperative vitamin D deficiency after Roux-enY gastric bypass surgery. Surgery for Obesity and Related Diseases 20073 434-437. (doi:10.1016/j.soard.2007.02.007)

8 Stein EM, Strain G, Ortiz D, Pomp A, McMahon DJ, Bockman R \& Silverberg SJ. Vitamin D insufficiency prior to bariatric surgery: risk factors and a pilot treatment study. Clinical Endocrinology 2009 71 176-183. (doi:10.1111/j.1365-2265.2008.03470.x)

9 Wortsman J, Matsuoka LY, Chen TC, Lu Z \& Holick MF. Decreased bioavailability of vitamin D in obesity. American Journal of Clinical Nutrition 200072 690-693.

10 Johnson JM, Maher JW, DeMaria EJ, Downs RW, Wolfe LG \& Kellum JM. The long-term effects of gastric bypass on vitamin D metabolism. Annals of Surgery 2006243 701-705. (doi:10.1097/ 01.sla.0000216773.47825.c1)

11 Fendrikova Mahlay N, Verka LG, Thomsen K, Merugu S \& Salomone M. Vitamin D status before Roux-en-Y and efficacy 
of prophylactic and therapeutic doses of vitamin D in patients after Roux-en-Y gastric bypass surgery. Obesity Surgery 200919 590-594. (doi:10.1007/s11695-008-9698-1)

12 Goldner WS, Stoner JA, Lyden E, Thompson J, Taylor K, Larson L, Erickson J \& McBride C. Finding the optimal dose of vitamin D following Roux-en-Y gastric bypass: a prospective, randomized pilot clinical trial. Obesity Surgery 200919 173-179. (doi:10. 1007/s11695-008-9680-y)

13 Avioli LV, Lee SW, McDonald JE, Lund J \& DeLuca HF. Metabolism of vitamin $\mathrm{D}_{3}{ }^{3} \mathrm{H}$ in human subjects: distribution in blood, bile, feces and urine. Journal of Clinical Investigation 1967 46 983-992. (doi:10.1172/JCI105605)

14 Van Groningen L, Opdenoordt S, van Sorge A, Telting D, Giessen A \& de Boer H. Colecalciferol loading dose guideline for vitamin D deficient adults. European Journal of Endocrinology 2010162 805-811. (doi:10.1530/EJE-09-0932)

15 Horst RL \& Hollis BW. Vitamin D assays and their clinical utility. In Vitamin D: Physiology, Molecular Biology and Clinical Applications, pp 239-271. Ed. MF Holick. New York, NY: Humana Press Inc., 1999.

16 Armas LAG, Hollis B \& Heaney RP. Vitamin $\mathrm{D}_{2}$ is much less effective than vitamin $\mathrm{D}_{3}$ in humans. Journal of Clinical Endocrinology and Metabolism 200489 5387-5391. (doi:10. 1210/jc.2004-0360)

17 Trevaskis NL, Charman WN \& Porter CJH. Lipid-based delivery systmes and intestinal lymphatic drug transport: a mechanistic update. Advanced Drug Delivery Systems 200860 702-716. (doi:10.1016/j.addr.2007.09.007)
18 Blomhoff R, Helgerud P, Dueland S, Berg T, Pedersen JI, Norum KR \& Drevon CA. Lymphatic absorption and transport of retinol and vitamin $\mathrm{D}_{3}$ from rat intestine. Biochimica et Biophysica Acta 1984 772 109-116. (doi:10.1016/0005-2736(84)90033-6)

19 Lo CW, Paris PW, Clemens TL, Nolan J \& Holick MF. Vitamin D absorption in healthy subjects and in patients with intestinal malabsorption syndromes. American Journal of Clinical Nutrition 198542 644-649.

20 Arnaud SB, Goldsmith RS, Lambert PW \& Go VlW. Evidence of an enterohepatic circulation in man. Proceedings of the Society for Experimental Biology and Medicine 1975149 570-572.

21 Clements MR, Chalmers TM \& Fraser DR. Enterohepatic circulation of vitamin D; a reappraisal of the hypothesis. Lancet 19841 1376-1379. (doi:10.1016/S0140-6736(84)91874-9)

22 Ledger JE, Watson GJ \& Compston JE. Biliary excretion of radioactivity after intravenous administration of $\left[\mathrm{H}^{3}\right] 25$-hydroxyvitamin $\mathrm{D}_{3}$ in man. Digestive Diseases and Sciences 198631 361-368. (doi:10.1007/BF01311670)

23 Heaney RP, Armas LAG, Shary JR, Bell NH, Binkley N \& Hollis BW. 25-Hydroxylation of vitamin $\mathrm{D}_{3}$ : relation to circulating vitamin $\mathrm{D}_{3}$ under various input conditions. American Journal of Clinical Nutrition $2008 \mathbf{8 7} 1738-1742$.

Received 16 February 2011

Accepted 20 February 2011 